Dharmaveer Singh ${ }^{1}$, Sanjay K.Jain ${ }^{2}$, R.D.Gupta ${ }^{3}$

${ }^{1}$ GIS Cell, Motilal Nehru National Institute of Technology Allahabad - 211004, (India)

*Corresponding author: e-mail: veermnnnit@gmail.com

2 Water Resources Systems Division, National Institute of Hydrology,

Roorkee - 247667 (India), e-mail: sanjay.nih@nih.ernet.in

${ }^{3}$ Department of Civil Engineering, Motilal Nehru National Institute of Technology,

Allahabad - 211004, Uttar Pradesh (India), e-mail: gupta.rdg@gmail.com

\title{
GLOBAL CLIMATE MODEL:
}

\section{A COMPREHENSIVE TOOL IN CLIMATE CHANGE IMPACT STUDIES}

\begin{abstract}
There is growing concern, how and to what extent future changes in climate will affect human society and natural environments. Continuous emissions of Green House Gasses (GHGs) at or above current rates will cause further warming. This, in turn, may modify global climate system during $21^{\text {st }}$ century that very likely would have larger impacts than those observed during $20^{\text {th }}$ century. At present, Global Climate Models (GCMs) are only the most reliable tools available for studying behaviour of the climate system. This paper presents a comprehensive review of GCMs including their development and applications in climate change impacts studies. Following a discussion of the limitations of GCMs at regional and local scales, different approaches of downscaling are discussed in detail.
\end{abstract}

\section{KEY WORDS: Climate, Green House Gasses, Global Climate Models}

\section{INTRODUCTION}

Significant increase in concentration of Green House Gases (GHGs) i.e. carbon dioxide $\left(\mathrm{CO}_{2}\right)$, methane $\left(\mathrm{CH}_{4}\right)$ and nitrous oxide $\left(\mathrm{N}_{2} \mathrm{O}\right)$ and aerosols in the Earth's atmosphere was found in Post-Industrial Revolution era due to burning of fossil fuels, deforestation and land use practices [Loaiciga et al., 1996]. In 1750 $\mathrm{AD}$, the concentrations of $\mathrm{CO}_{2}, \mathrm{CH}_{4}$ and $\mathrm{N}_{2} \mathrm{O}$ were 280 ppm, 715 ppb and 270 ppb whereas in 2005, these were 379 ppm, 1774 ppb and 319 ppb respectively. The increase in GHGs occurred more rapidly after 1950 s as $70 \%$ of such increase is reported in between 1970 to 2004. The increased concentrations of GHGs in atmosphere have altered global energy balance and resulted into warming of the atmosphere. This in turn raised surface temperature and attributed to climate change [IPCC, 2007].

Natural resources and ecological resources of the Earth including human are greatly affected by climate change occurred in the recent past [Kislov et al., 2009]. It not only altered phenological development of flora but also caused extinctions of several species of flora and fauna. However, some species are still in danger. According to Hartmann et al [2013] human society witnessed huge loss of lives, mental and emotional distress, extensive damages to crops and properties due to changes in key climatic variables and related phenomenon.

There is growing concern, how and to what extent future changes in climate will affect human society and natural environments. Definitely, continuous GHGs emissions at or above current rates will cause further warming. This, in turn, may modify global climate system during $21^{\text {st }}$ century that very likely would have larger impacts than those observed during $20^{\text {th }}$ century. Global Climate Models (GCMs) sometimes also referred as General Circulation Models or coupled 
Atmosphere Ocean Global Climate Models (AOGCMs) are currently the most reliable tools available for studying behaviour of the climate system, its components and their interactions and for deriving projections of meteorological variables [Hewitson and Crane, 1996; Solaiman, 2011]. These models are based on physical laws of radiative transfer and thermodynamic. They are run for accounting effect of GHGs and aerosols in the atmosphere and used to investigate anticipated behaviour of complex atmosphere-land-ocean systems under changing climatic conditions.

This paper presents an overview of GCMs in climate change impacts studies. The origin and stages in development of GCMs is described in section 2. Section 3 starts with the applications of GCMs in climate change studies including their limitations. Need of downscaling along with different downscaling techniques is addressed in section 4. Conclusion drawn from this study is presented in section 5 respectively.

\section{ORIGIN AND STAGES IN DEVELOPMENT OF GCMS}

The first GCMs developed in the 1960s based on work of Phillips (1956) and many others were simple Atmospheric Global Climate Models (AGCMs) [Barry and Carleton, 2001]. They were used to simulate average synoptic-scale (i.e. $10^{4}-10^{6} \mathrm{~km}^{2}$ spatial scale) atmospheric circulation patterns for specified external forcing conditions. The growing computational power of digital computers along with improved algorithms and understanding of the climate system has notably enhanced the modelling capability of GCMs. The chronological developments of GCMs are illustrated in Fig. 1. During mid 1980s, atmospheric and land components of the climate system were integrated in GCMs. Similar to AGCMs, Oceanic Global Climate Models (OGCMs) were also developed during this period. The late 1990s was an important phase in the history of GCMs where AGCMs and OGCMs were coupled and complex coupled Atmosphere Ocean Global Climate
Models (AOGCMs) or simply abbreviated as GCMs came into picture. Incorporating all components of climate systems and their feedback interactions in GCMs have always been a challenge however, to the some extent these problems are solved in present days GCMs [IPCC, 2001]. They are designed to incorporate complex biogeochemical feedbacks (for example, carbon cycle, sulphate aerosols, non sulphate aerosols etc.) which determine the atmospheric composition and the nature of the land vegetation in addition to the major components (atmosphere, land, ocean, cryosphere and biosphere) of the climate systems.

AGCMs which explicitly account dynamical processes of the atmosphere simulate atmospheric processes in three dimensions (3D). Fundamental physical laws; conservation of energy, mass, and momentum are used to depict behaviour of the atmosphere. This includes derivation of a series of nonlinear prognostic equations that are solved to obtain a trajectory of the global climate compatible with the external forcings under given initial conditions [Barry and Carleton, 2001]. The earth's surface (globe) is divided into a series of grid boxes $\left(1^{\circ}\right.$ to $\left.4^{\circ}\right)$, extending vertically into the atmosphere. The size and number of the grid boxes are limited by the amount of computer power available and the time period over which the model is integrated [Hartmann, 1994]. Further, atmosphere is divided into different vertical layers (commonly 10-20) based on height or pressure levels with more levels near the earth's surface. Equations are solved at each grid point and at each vertical level at a preset time interval (typically 20-30 min) with vertical and horizontal exchanges of energy, mass, and momentum computed for all points at each time interval [Bradley, 1999].

There are some physical processes often called sub-grid scale processes (e.g. cumulus convection, surface heat and moisture fluxes, and terrain-induced vertical motion) occur at scales much smaller than the grid resolution and so cannot be explicitly simulated 


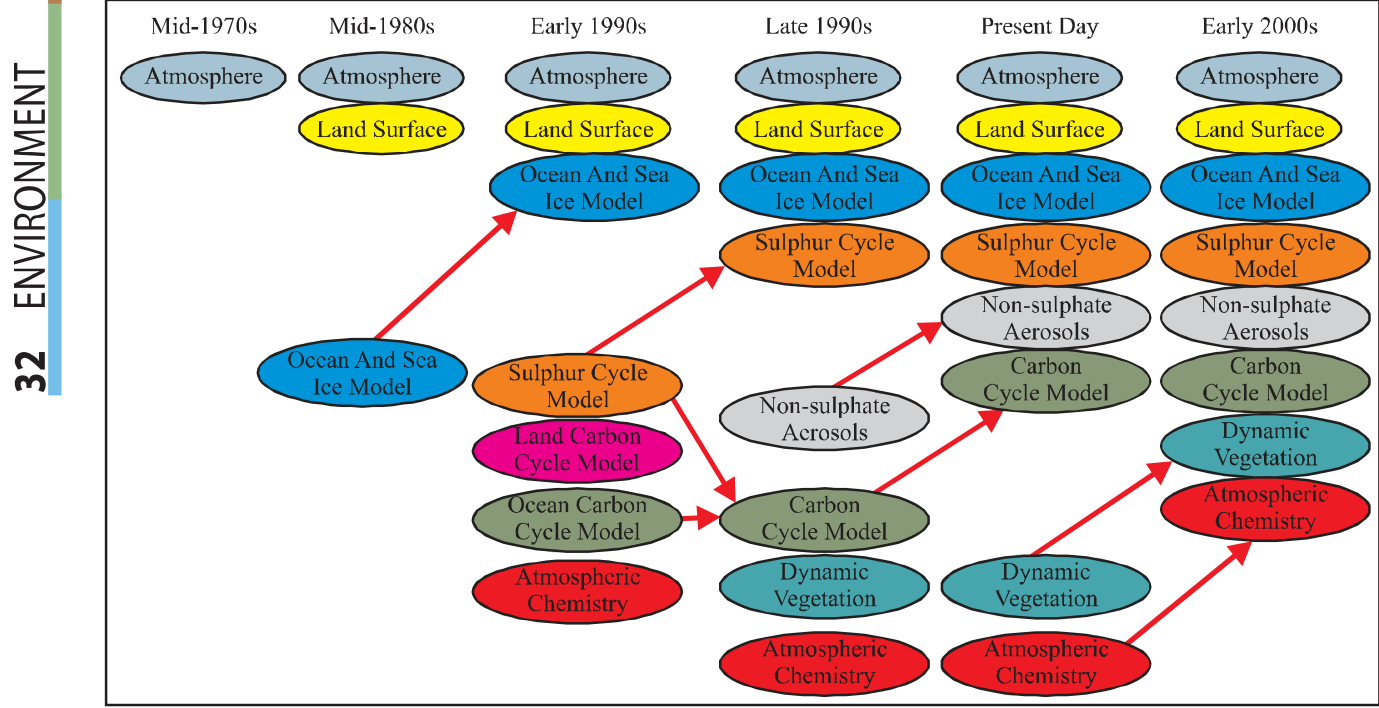

Fig. 1. Chronological development in Global Climate Models [IPCC, 2001]

[Hartmann, 1994]. Further, these unresolved sub-grid scale processes or phenomenon are parameterized accounting knowledge of the state of the atmosphere at the grid scale by means of simple mathematical relationships [McGuffie and Henderson-Sellers, 1997]. Uncertainty involved in parameterizations of these processes determines the behaviour of the climate model.

Oceanic Global Climate Models or Ocean General Circulation Models (OGCMs) are constructed by applying the same basic techniques used for AGCMs. They assume fixed wind stress, air temperature, air humidity precipitation and radiative forcing. Together these determined the flux of momentum, heat, and freshwater at the surface that are the key driving forces of the ocean circulation However, their development has been lagged behind AGCMs and this has been attributed to non availability of observed records of oceanic parameters (sea surface temperature, salinity etc.) and computational problems required in simulation of oceanic processes [Hartmann, 1994].

The speed of many important ocean currents is small and therefore difficult to observe with great precision. Therefore, finer spatial resolution is required to simulate effectively the important scale of motion (oceanic eddies) that are $<50 \mathrm{~km}$ across [Bradley, 1999]. Besides, OGCMs attain a state of stable climatology after very long time integration because the deep circulation in the oceans requires centuries to spin up from rest or to respond to changed forcings. As a result, this long integration time and the high spatial resolution required for realistic simulations of ocean circulation require substantial and sophisticated computer resources for modelling [Hartmann, 1994]. These problem can be resolved by using a series of parallel computers (employing $>100$ processors simultaneously).

\section{Coupling of AGCMs and OGCMs}

Coupling of AGCMs and OGCMs may be performed in four ways depending upon the complexity involved in exchange of heat and moisture [Bradley, 1999]. It has been shown in Fig. 2. In first level (simple coupling), surface temperature of the ocean is set and the ocean region ('swamp ocean') of the model interacts with the atmosphere only in terms of moisture exchange. In second 

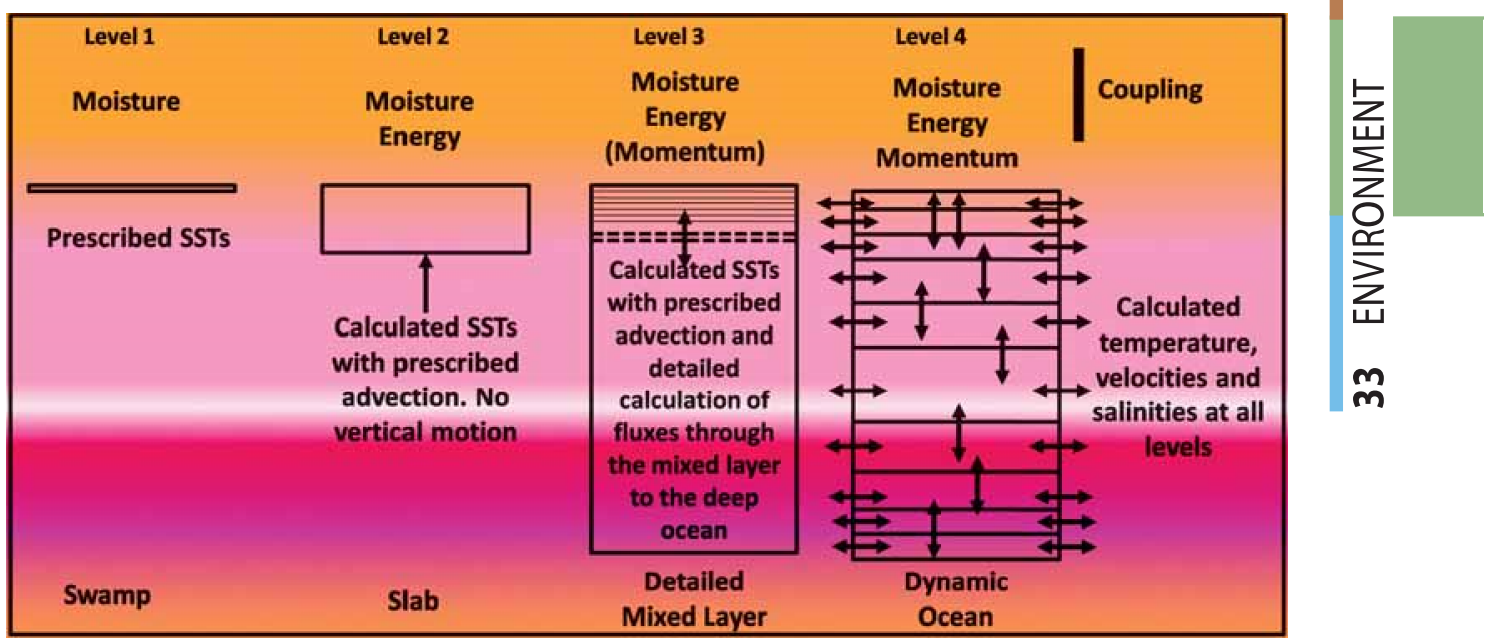

Fig. 2. Coupling with atmosphere in various types of ocean model [McGuffie and Henderson-Sellers, 1997]

level, exchange of both heat and moisture occurs with the atmosphere from a 'slab ocean' that has been specified as a layer of fixed depth (50-100 m). This mechanism of heat and moisture exchange enables Seas Surface Temperature (SSTs) to vary as the model run progresses. The nonexistence of vertical motion in such models restricts the exchange of heat from the deep ocean and merely exchange of horizontal energy fluxes occur. The mixed layer ocean (third level) is a further improvement, also involving prescribed horizontal advection, but with computation of fluxes to and from the deep ocean. In fourth level (fully developed coupled GCMs), the ocean has internal dynamics in three dimensions with calculated temperature, velocity and salinity in all directions. Further, exchanges of energy, moisture, and momentum take place at the ocean-atmosphere interface.

The major problem encountered in coupling of atmospheric and oceanic processes is large differences in estimated response times for different components of the climate systems (Fig. 3). The estimated response times for the atmosphere, surface snow and ice, litho-biosphere and lakes have been found in the range of $10^{5} \mathrm{~s}$ to $10^{6} \mathrm{~s}$. Conversely, glaciers, ice sheets and the deep ocean have response times of order $10^{9} \mathrm{~s}$ to $10^{11-12} \mathrm{~s}$ respectively. The problem of mismatch in scale of response times is resolved by coupling models of each system 'asynchronously'. It involves operation of an atmospheric model for a time appropriate for that system and then uses the resulting atmospheric conditions as input to a model of the system operating on a different timescale [Bradley, 1999].

The coupled GCMs inherit substantial errors (transfer of errors from both the component) in the simulation of sea-surface temperature and sea ice extents. So, they are unable to simulate present climate accurately. This problem has been fixed by a technique known as flux correction or flux adjustment. Flux adjustments that are non-physical in nature are explicitly added in the models to give a stable and realistic simulation of present surface climate (especially the sea surface temperature and sea ice cover). These adjustments are considered as poor solutions in the validation process because they have introduced model uncertainties and violated the physical laws of conservation of mass and energy. However, the newest generation of GCMs has eliminated the need for flux adjustment [IPCC, 2001]. 


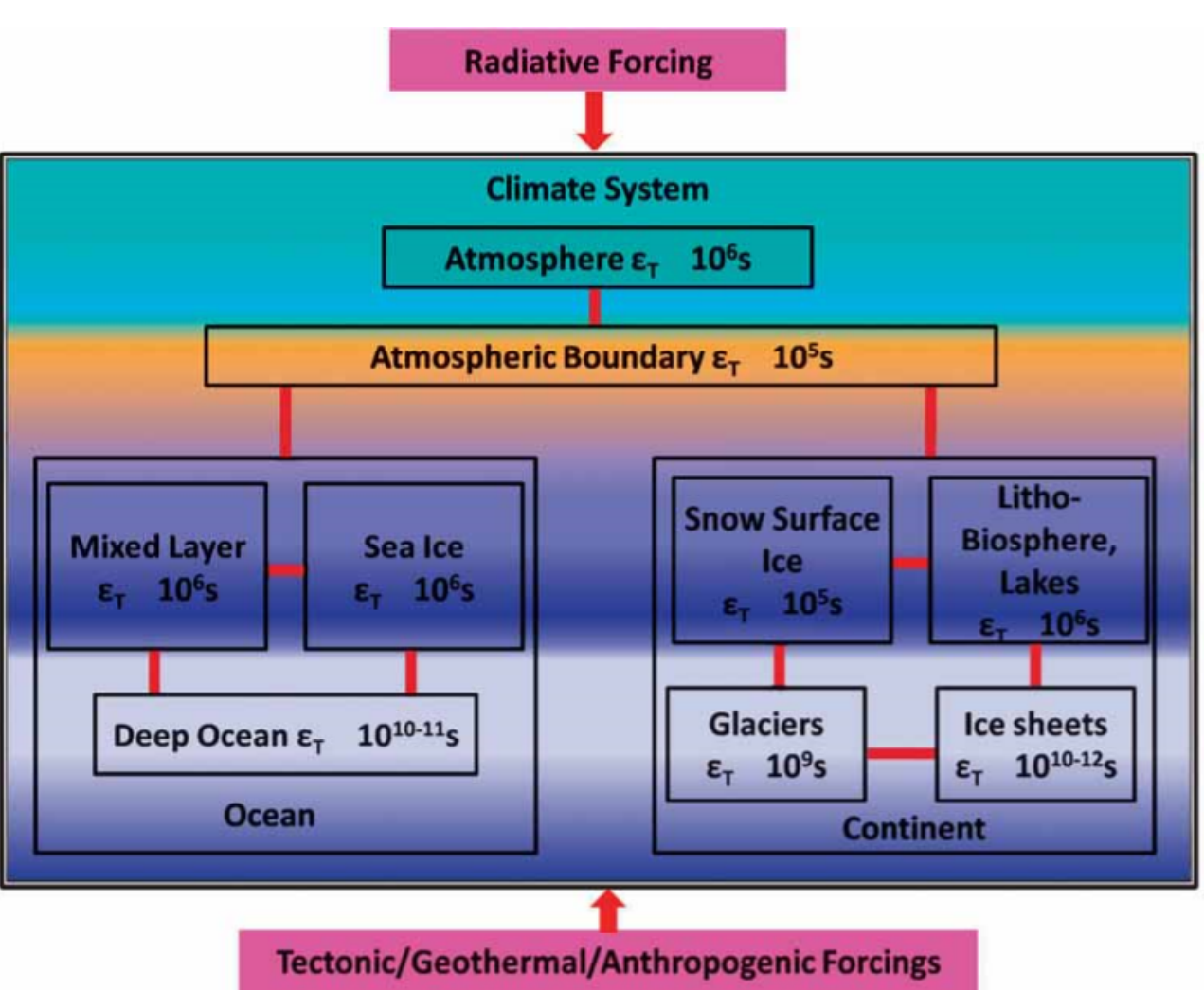

Fig. 3. Estimated response for different components of climate system [Saltzman, 1985]

\section{GCMs and Emission Scenarios}

After a model (GCM) is developed and validated, it can be used to evaluate alternative scenarios. Scenarios are alternative images of how the future might unfold. They have been generated based on certain assumptions (future trends in energy demand, emissions of GHGs, land use change and the behavior of the climate system over long time scales) for explicit use in investigating the likely consequence of anthropogenic climate change [IPCC, 2001]. IPCC which had initially used four man made future emission scenarios in its First Assessment Report (AR1), presented six alternative scenarios ranging from IS92a to IS92f in 1992. These scenarios embodied wide array of assumptions affecting how future GHGs emission might evolve. Out of these scenarios IS92a (Business as Usual) was widely adopted by the scientific community. In the light of improved understanding of climate dynamics and driving forces of emissions, these scenarios were re-evaluated and led to the release of Special Report on Emission Scenarios (SRES) in year 2000. Based on this report, a new set of scenarios was developed with four story lines (families) i.e. A1, A2, B1 and $B 2$ to represent the range of driving forces and emission in the scenario literature. They reflect current understanding and knowledge about underlying uncertainties. However, in year 2013 IPCC replaced SRES scenarios with four Representative Concentration Pathways (RCPs) [IPCC, 2013]. These are RCP2.6, RCP4.5, RCP6.0 and RCP8.5 respectively. They are named after a possible range of radiative forcing values in the year 2100 relative to pre-industrial values $\left(+2.6 \mathrm{~W} / \mathrm{m}^{2},+4.5 \mathrm{~W} / \mathrm{m}^{2}\right.$, $+6.0 \mathrm{~W} / \mathrm{m}^{2}$ and $+8.5 \mathrm{~W} / \mathrm{m}^{2}$ ) [Urich et al., 2014].

The requirements of large computational powers (super computers) have restricted their expansion only to the few research 
organisations or groups. However, notable increase in number of such research organizations is observed with successive IPCC assessments. Starting with five groups and eight models in 1990 (First Assessment Report), it has increased to 27 groups and 61 models in 2014 (Fifth Assessment Report) [Urich et al., 2014]. These GCMs have been used to simulation the climate of $20^{\text {th }}$ century (known as $20^{\text {th }}$ Century Climate in Coupled Models (20C3M) experiment) and project several marker scenarios for the future based on IPCC SRES. Coupled Model Intercomparison Project Phase 3 (CMIP3) and Coupled Model Intercomparison Project Phase 5 (CMIP5) coordinated by IPCC provide a GCM data base for scientific interpretations [IPCC, 2013]. These data are made available to general scientific community by IPCC Data Distribution Centre (http://www.ipccddc.cru. uea.ac.uk/).

\section{APPLICATIONS OF GCMS IN CLIMATE CHANGE STUDIES}

GCMs have been widely used in climate change studies and their applications can vary from simulation and modelling of climate variables to prediction of stream flow and estimation of crop yields. For examples, the study conducted by Kripalani et al [2007a] over East Asian region based on IPCC AR4 (CMIP 3) models predicted significant change in mean annual precipitation. However, changes in mean precipitation varies from model to model (-0.6\% for CNRM-CM3 and $14 \%$ for ECHO-G and HadCM3) respectively. In another study undertaken over South Asia, a rise of $8 \%$ in mean monsoon precipitation was reported under doubling of $\mathrm{CO}_{2}$ scenario [Kripalani et al., 2007b]. Based on the result derived from 5 GCMs, Sarthi et al [2012] observed rise in mean annual temperature (in the range of $0.6^{\circ} \mathrm{C}$ to $1.8^{\circ} \mathrm{C}$ ) over the Himalayan and Tibetan region for the future period. Kumar et al [2013] have used 22 GCMs and three Regional Climate Models (RCMs) for predicting future patterns of temperature and precipitation under A1B emission scenario over India. This study based on ensembles of
22 GCMs (GCM EM $\left._{1}\right)$ as well as 3 RCMs (RCM EM $\left._{1}\right)$ indicates rise in annual surface temperature with respect to baseline period (1970-1999). The predicted increase in $\mathrm{GCM}_{\mathrm{EM}} / \mathrm{RCM}_{\mathrm{EM}}$ for the periods 2010-2039, 2040-2069 and 2070-2099 with respect to baseline period is $1.1{ }^{\circ} \mathrm{C} / 1.1^{\circ} \mathrm{C}, 2.5^{\circ} \mathrm{C} / 2.2^{\circ} \mathrm{C}$ and $3.9^{\circ} \mathrm{C} / 3.2$ ${ }^{\circ} \mathrm{C}$ respectively. Similarly, rise in mean annual precipitation including monsoon season is also predicted by the end of $21^{\text {st }}$ century. However considerable spatial variability is observed in pattern of precipitation.

Recently, the responses of East Asia summer precipitation to global warming have been studied by Qu et al [2014] using ensembles of 16 CMIP 5 models. The results derived from this study predicts increase in overall summer precipitation over East Asia. The study of Wei et al [2009] conducted over China using high resolution Providing Regional Climates for Impacts Studies (PRECIS) model under A2 and B2 emission scenarios has revealed rise in mean annual temperature (from 1.3 ${ }^{\circ} \mathrm{C}$ to $4.5^{\circ} \mathrm{C}$ under $\mathrm{A} 2$ and from $1.5^{\circ} \mathrm{C}$ to 3.4 ${ }^{\circ} \mathrm{C}$ under B2), precipitation (from 5\% to $17 \%$ under $\mathrm{A} 2$ and from $4 \%$ to $9 \%$ under B2) and radiation (0.5\% to $1.1 \%$ under $\mathrm{A} 2$ and $0.5 \%$ to $0.9 \%$ under B2) for the periods of $2020 \mathrm{~s}$ (2011-2040), 2050s (2041-2070) and 2080s (2071-2100) respectively. A comprehensive study of future ( $21^{\text {st }}$ century) temperature change for Northern Eurasia using different CMIP5 models has been done by Miao et al [2014]. This study predicts rise in surface air temperature with the rates of $1.03{ }^{\circ} \mathrm{C} / 100$ year, $3.11^{\circ} \mathrm{C} / 100$ year and $7.14{ }^{\circ} \mathrm{C} / 100$ year under the RCP 2.6, RCP 4.5 and RCP 8.5 scenarios, respectively. The projected rate of increase in temperature has been found comparatively higher for high latitude regions than the regions of low latitudes. In addition, the spring season contributes most to the decadal warming occurring under the RCP 2.6 and RCP 4.5 scenarios, while the winter season contributes most to the decadal warming occurring under the RCP 8.5 scenario.

In this line of research, Urrutia and Vuille [2009] have presented climate change projections 
(for temperature and precipitation) for the tropical Andes (mountainous region) using a RCM. The results derived from GCMs have shown significant changes in the frequency and magnitude of weather and climate extremes in future. There is high confidence that decrease in diurnal temperature range along with very cold days and increase in warm days coupled with increased rainfall intensity may occur in different parts of the Earth. Similar kinds of studies were also undertaken in other parts of the world; Europe by Ruosteenoja et al [2007], Africa by Diallo et al [2012] and South America by Solman [2013] respectively.

Further, the outputs of GCMs are readily applied in investigating consequences of future climate change on hydrology, glaciers, ecology, forestry, agriculture and water resource management studies respectively.

\section{Limitations of GCMs}

Despite notable development, GCMs still have some limitations as discussed below:

I. Most of GCMs considered in CMIP3 projects have included interactive land surface schemes i.e. fluxes from the land surface is felt by the modeled atmosphere. These schemes are quite sophisticated as they incorporate different vegetation types, interaction between solar radiation and canopy cover, transpiration, effect of soil moisture etc. However, carboncycle feedbacks are not generally modeled and possible changes in vegetation cover are not presently taken in account in climate change simulations [Brown et al., 2008].

II. GCMs are quite good in simulating planetary scale features but fail to resolve local scale topographic and sub-grid-scale processes and dynamics such as clouds, Jet Stream, El Nino Southern Oscillation (ENSO) because of their coarse spatial resolution. The decrease in spatial accuracy of GCMs simulated climate variables occurs from continental to local scale. This restricts the direct applications of GCM's outputs in regional climate change impact studies.
III. Due to simplified approximation of radiant-energy transfer and sub-grid scale parameterizations (e.g. cloud formations and dissipation, cumulous convections and turbulence), the large scale climate variables such as wind, temperature, humidity and sea level pressure are modeled more accurately by GCMs than the smaller scale hydrological variables i.e. precipitation, evaporation, evapotranspiration, soil moisture and discharge [Solaiman, 2011].

IV. GCMs have been found more skillful in predicting means (average) of temperature and precipitation than any higher order of statistics i.e. variability. Besides, higher confidence is achieved in estimation of temperature than precipitation. Extreme events such as length of dry spell, wet spell length and frequency of heavy rainfall events are poorly simulated by models even though mean annual precipitation is reasonably well simulated.

V. Present day GCMs usually make long term prediction of climate change and lack in ability of predict near term climate change i.e. climate variables on decadal time scales [Brown et al., 2008]. However, emphasis has been focused on changes in climate that might occur within the span of few decades than century-length periods.

\section{DOWNSCALING}

GCMs as discussed above have been found incapable for detailed assessment of land surface processes and climate change impacts at local to regional scales, especially in regions with heterogeneous land cover and diverse topography [Wilby et al., 2004]. As a result techniques usually known as 'downscaling' have been invented for narrowing the gap between the scale of GCMs and required resolution for impact assessment [Wilby and Dawson, 2013]. In downscaling, Large Scale Atmospheric Variables (LSAVs) are applied to predict local meteorological conditions [Willby and Dawson, 2013]. Thus, increase in spatial resolution of GCM's output is achieved. 
This is mainly on the availability of archived observational and GCM data as both are required to generate future climate scenarios [Willby and Dawson, 2007]. The capability of downscaling in providing additional details can inform site specific assessment and management of climate risk. Based on literature review, downscaling can be grouped into two broad categories; dynamical and statistical downscaling [Fowler et al., 2007].

\section{Dynamical Downscaling}

Dynamical Downscaling (DD) involves development and use of Limited Area Models (LAMs) or Regional Climate Models (RCMs) for generating high resolution (10-50 km) outputs based on atmospheric physics over a region using GCM fields as boundary conditions [Giorgi and Mearns, 1999]. The extraction of local-scale information from large-scale GCM data is achieved by adopting following approaches; (I) running a regional scale LAM with coarse GCM data as geographical or spectral boundary conditions, (II) performing global-scale experiments with high resolution Atmosphere-GCM (AGCM), with coarse GCM data as initial (as partially and boundary) conditions and (III) the use of a variable-resolution global model with the highest resolution over the area of interest [Solaiman, 2011].

RCMs are more or less similar to GCMs in principles. They are nested within GCMs. This is performed to save processing time and costs in lieu of running the two models in successive fashion. Initial and boundary conditions required in calibration of RCMs are generated from the GCM or historical data base (NCEP/ NCAR) [Brown et al., 2008]. The individual choice of domain size controls the divergence between the RCMs and their driving GCMs [Jones et al., 1997]. However, additional detail is also provided concerning the land use, coast lines, topographical structures and better resolved spatial gradients in physical fields [Kumar et al., 2013]. It can bring significant change in regional flow patterns and increase the importance of local feedback processes such as snow-albedo/air temperature or soil moisture/air temperature feedbacks.
RCMs present a better description of topographic phenomena such as orographic effects and meso-scale circulation pattern than GCMs due to their high spatial resolution and ability of simulating finer dynamical processes. But in terms of temporal resolution, they have been found more skillful at monthly or coarser time scales than daily. The major drawbacks of RCM are its complex design and computationally expensive nature [Hewitson and Crane 1996].

However, there are certain issues which are still unresolved and are also plaguing RCMs [Brown et al., 2008]. These include:

I. Parameterization of convective precipitation, mainly over tropics where convection is major source of moisture transport.

II. RCMs inherited biases systematically transmitted by GCMs in simulation of precipitation including extreme events. Therefore, use of model ensembles is to be recommended for a realistic assessment of climate change.

III. Based on large scale conditions defined by the host GCMs, RCMs assume fixed lateral fluxes into and out of their domain. Further, it is believed that evolution of climate within the RCM does not affect the output provided by the GCM. However, it is not true in reality.

IV. Because of computationally expensive nature, model integrations have, until recently, been restricted to'time slices'; normally $\sim 30$ years for a control or'baseline' climate from 1961-1990 and for a changed climate from 2070-2100 (Fowler et al. 2007). Scenarios for other periods are generated using 'pattern scaling' where changes are scaled according to the temperature signal modeled for the intervening period, assuming a linear pattern of change.

\section{Statistical Downscaling}

Statistical Downscaling (SD) technique is supported by the view; the regional climate is conditioned by large scale climate state and regional/local physiographic features 
GEOGRAPHY. ENVIRONMENT. SUSTAINABILITY.

02 (08) 2015

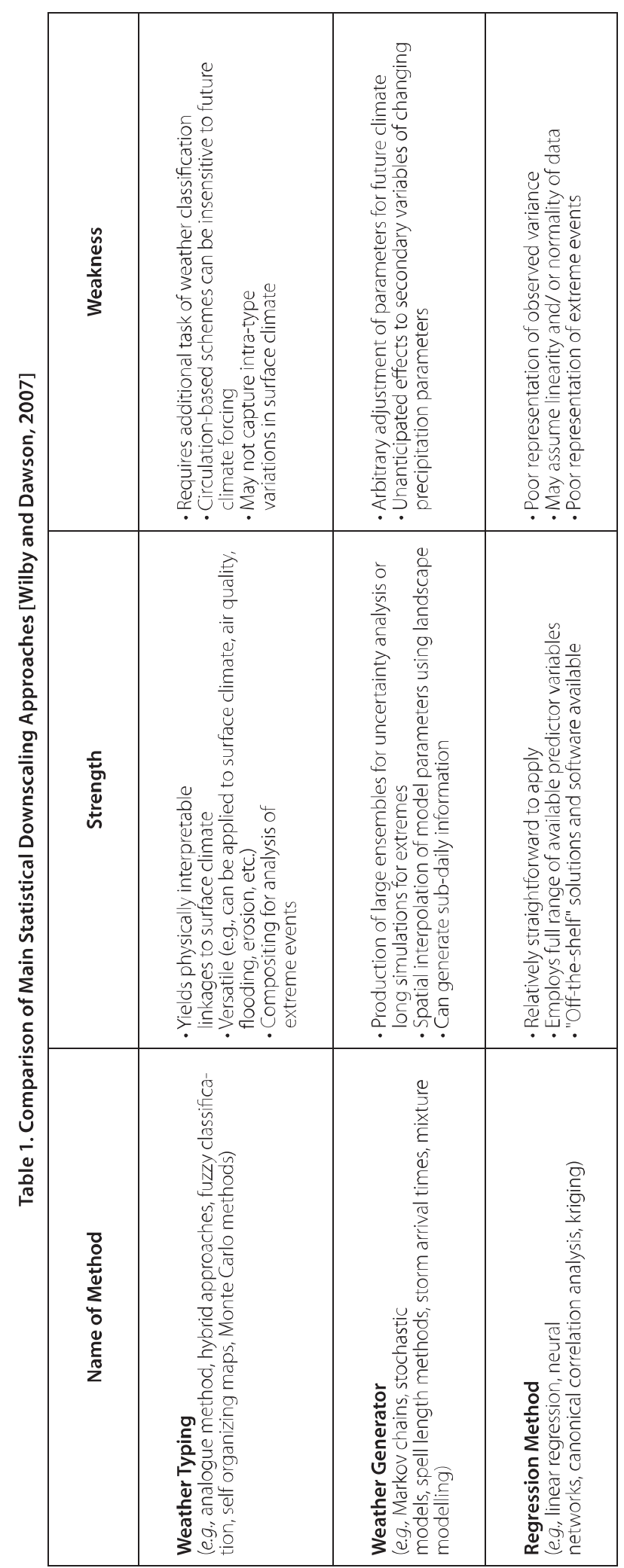


(e.g. topography, land-sea distribution and land use/land cover). In this technique, large scale atmospheric variables (predictors) of GCMs such as mean sea level pressure and geopotential heights are related to stationscale climate variables (predictands) such as temperature and precipitation based on statistical/empirical relationship [Raje and Mujumdar, 2011]. Based on these statistical/ empirical relationships, local scale predictands (e.g. temperature and precipitation) can be downscaled at specific site or station. SD has shown advantage over DD approach as it is faster and simpler in use, less computationally expensive, provide site specific information and applicable for uncertainty and risk analyses [Yarnal et al., 2001]. The requirement of long time series of historical weather stations data is a serious drawback of this approach.

Further, SD methodologies have been grouped into three sub-categories; weather typing, weather generator and regression/ transform function [Ghosh and Mujumdar, 2007]. The strength and weakness of each approach (shown in Table 1) has been reviewed in detail by Hewitson and Crane [1996] and Wilby and Dawson [2007].

Weather Typing establishes a sensible link between climate on large scale and weather at local scale [Wilby and Dawson, 2007]. It involves grouping of days into a finite number of discrete weather types or 'states' according to their synoptic similarity whereas weather states are defined either by applying cluster analysis to atmospheric field or using subjective circulation classification schemes [Wilby et al., 2004]. The generated weather patterns are grouped into weather classes according to their similarity with nearest neighbours or a reference sets. It assumes that characteristics of weather class remain unchanged [Fowler et al., 2007].

The construction of future regional climate scenarios includes resampling of observed variables distribution or synthetically generated data (from Monte Carlo techniques) conditioned on daily weather patterns and associated with a given atmospheric circulation pattern produced by a GCM. The mean or frequency distribution of the local climate is then derived by weighting the local climate states with the relative frequencies of the weather classes simulated by GCM [Ghosh and Mujumdar, 2007].

This technique of downscaling provides multivariables and multi-sites information [Wilby et al., 2004]. However, it has shown limited success in downscaling'rare' events (e.g. wet and dry spells) and precipitation changes produced by changes in the frequency of weather patterns are seldom consistent with the changes produced by host GCM [Wilby and Dawson, 2007]. This may be attributed to the relationship established between stationary circulation and surface climate. The methods based on this approach are; analogue method, hybrid approaches, fuzzy classification, self organizing maps and Monte Carlo methods respectively.

Weather Generators are stochastic models where climatic variables are conditioned by specific climatic events i.e. precipitation occurrence instead of weather pattern [Fowler et al., 2007]. The daily climate is defined by outcomes on previous days. This involves twostate, first order Markow chains for simulating precipitation occurrence, gamma distribution predicting amount of precipitation on wet days and first-order trivariate autoregression conditioned by precipitation occurrence for simulating temperature and radiation components [Wilby and Dawson, 2007].

Recently, this has been found that weather typing scheme may also be used to drive weather generator models [Fowler et al., 2007]. The study of Corte-Real et al [1999] used daily weather patterns derived from principal components of mean sea level pressure to condition a weather generator model. Further, advancement in modelling of the autocorrelation structure of wet and dry days is observed where the probability of rain is conditioned by the current circulation pattern and the weather regime of the previous day. This has been found skillful in simulating fundamental characteristics of precipitation including distribution of wet 
and dry spell lengths. The major drawback of this approach is that this is defined by local climate relationships and so may not be automatically applicable in other climates. Besides, inter-annual variability is also not accurately represented and they are underestimated.

Regression/Transform Functions are one of the most popular and widely used approaches applied in downscaling of large scale climate variables simulated by GCMs. In this approach, a linear or non-linear link is developed between predictors and predictands of interest and focus on changes in the central tendency of predictands [Schoof et al., 2007]. There are different kinds of regression methods (based on choice of mathematical transfer functions, predictor variables and statistical fitting procedures) in practice which differ in complexity from simple multiple regression models to artificial neural networks, canonical correlation analysis and principal component analysis.

The methods based on this approach assume validity of the model parameters under future climate conditions similar with the weather typing methods. The choice of predictors and statistical forms affect the results of downscaling to the large extent. The major disadvantage of this approach is that it often explain only a fraction of the observed climate variability (especially in precipitation series) [Wilby and Dawson, 2007]. In spite of these limitations, the relative ease of application along with their use of observable trans-scale relationships have encouraged applications of these methods in downscaling of climate variables and performing impact assessment studies.

As discussed above, none of the approach (statistical downscaling approaches) has been found 'perfect' in downscaling and simulating climate variables for future periods. Therefore, attempts have been made to develop new approaches by combining one model with another. This may improve the simulation of variability as well as extremes. This has been confirmed by the study Kilsby et al [2007]. They observed that incorporation of a stochastic rainfall model into a weather generator has improved the simulation of both variability and extremes when compared to a simple Markov chain model. In this line of research Wilby et al [2002] have developed a hybrid model popularly known as 'Statistical Downscaling Model' abbreviated as SDSM. It is a combination of multiple regressions and stochastic weather generator based downscaling methods. It uses circulation patterns and moisture variables to condition local weather parameters and stochastic methods to inflate the variance of the downscaled climate series [Fowler et al., 2007].

\section{CONCLUSION}

This review summarizes the progress achieved on Global climate modelling since the early efforts at the beginning of the 1960s until now. Results predicted by earlier GCMs inherited large uncertainties as they made simple approximation of physical processes and corrected it by flux adjustments. However, the newest generation of GCMs has eliminated the need for flux adjustment and relatively more realistic in their long-term prediction. The problems related to current capacity of GCMs such as failure in simulation of local scale topographic and subgrid-scale processes and dynamics because of their low resolution have restricted their successful applications only to global and continental scales. The problem of discordant scales can be solved by using downscaling techniques. However, this may increase uncertainty in projection. Despite of these limitations, GCMs and their outputs have been found suitable in studying impacts of climate change hydrology, glaciers, ecology, forestry, agriculture and water resource management studies.

\section{ACKNOWLEDGEMENT}

Authors acknowledge the financial support in the form of fellowship provided by University Grant Commission (UGC), Government of India to Mr. Dharmaveer Singh as Research Fellow for carrying out this research. 


\section{REFERENCES}

1. Barry R.G., Carleton A.M. (2001). Synoptic and dynamic climatology. Routledge, London and New York.

2. Bradley R.S. (1999). Paleoclimatology:Reconstructing Climate of the Quaternary. Harcourt Academic Press.

3. Brown C., Greene A., Block P., Giannini A. (2008). Review of downscaling methodologies for Africa climate applications. IRI Technical Report: IRI Downscaling Report. Available at http://iri. columbia.edu/docs/publications/IRI_Downscaling_Review.pdf. (Accessed on the 2012-06-15).

4. Corte-Real J., Qian B., Xu H. (1999). Circulation patterns, daily precipitation in Portugal and implications for climate change simulated by second Hadley Centre GCM. Climate Dynamics, Vol. 15, pp. 921-935.

5. Diallo I., Sylla M.B., Giorgi F., Gaye A.T., Camara M. (2012). Multimodel GCM-RCM ensemble-based projections of temperature and precipitation over West Africa for the early $21^{\text {st }}$ century. International Journal of Geophysics, doi: 10.1155/2012/972896.

6. Fowler H.J., Blenkinsop S., Tebaldi C. (2007). Linking climate change modelling to impacts studies: recent advances in downscaling techniques for hydrological modelling. International Journal of Climatology, Vol. 27 (12), pp. 1547-1578.

7. Ghosh S., Mujumdar P.P. (2007). Nonparametric Methods for Modeling GCM and Scenario Uncertainty in Drought Assessment. Water Resources Research, Vol. 43, pp. W07405, DOI:10.1029/2006WR005351.

8. Giorgi F., Mearns L.O. (1999). Regional climate modelling revisited. An introduction to the special issue. Journal of Geophysical Research, Vol. 104, pp. 6335-6352.

9. Hartmann D.L. (1994). Global Physical Climatology. Academic Press, California USA.

10. Hartmann D.L. et al. (2013). Observations: Atmosphere and Surface Supplementary Material, In: Climate Change 2013: The Physical Science Basis. Contribution of Working Group I to the Fifth Assessment Report of the Intergovernmental Panel on Climate Change, Stocker, T.F. et al., (Eds.). Available online at www.climatechange2013.org and www.ipcc.ch. (Accessed on the 2014-03-16).

11. Hewitson B.C., Crane R.G. (1996). Climate downscaling: techniques and application. Climate Change, Vol. 7, pp. 85-95.

12. IPCC (2001). Climate change 2001: the scientific basis. Contribution of Working Group 1 to the Third Assessment Report of the Intergovernmental Panel on Climate Change, edited by Houghton JT et al. Cambridge University Press, Cambridge, UK, and New York, USA.

13. IPCC (2007). Climate Change 2007. Impacts, adaptation and vulnerability. Contribution of working group II to the Fourth Assessment Report of the Intergovernmental Panel on Climate Change, edited by M. Parry et al., Cambridge University Press, UK. 
14. IPCC (2013). Scenario Process for AR5. Available online at http:// sedac.ciesin.columbia. edu/ddc/ar5_scenario_process/RCPs.html. (Accessed on 2014-02-08).

15. Jones R.G., Murphy J.M., Noguer M., Keen B. (1997). Simulation of climate change over Europe using a nested regional-climate model. II: Comparison of driving and regional model responses to a doubling of carbon dioxide. Quarterly Journal of the Royal Meteorological Society, Vol. 123, pp. 265-292.

16. Kilsby C.G., Jones P.D., Burton A.A., Ford C., Fowler H.J., Harpham C., James P., Smith A., Wilby R.L. (2007). A daily Weather Generator for use in climate change studies. Environmental Modelling and Software, Vol. 22, pp. 1705-1719.

17. Kislov A., Evstigneev V., Surkova G. (2009). Experience of the forecast of water and power resources changes at warming of the 21st century. Science in China Series E: Technological Sciences, Vol. 52 (11), pp. 3224-3233., doi:10.1007/s11431-009-0372-1

18. Kripalani R.H., Oh J.H., Chaudhari H.S. (2007a). Response of the East Asian summer monsoon to doubled atmospheric $\mathrm{CO}_{2}$ : coupled climate model simulations and projections under IPCC AR4. Theoretical and Applied Climatology, Vol. 87 (1), pp. 1-28, doi: 10.1007/s00704-006-0238-4

19. Kripalani R.H., Oh J.H., Kulkarni A., Sabade S.S., Chaudhari H.S. (2007b). South Asian summer monsoon precipitation variability: coupled climate model simulations and projections under IPCC AR4. Theoretical and Applied Climatology, Vol. 90 (3), pp. 133-159, doi: 10.1007/s00704-006-0282-0.

20. Kumar P., Wiltshire A., Mathison C., Asharaf S., Aherns B., Lucas-Picher P., Christensen J.H., Gobiet A., Saeed F., Hagemann S., Jacob D. (2013). Downscaled climate change projections with uncertainty assessment over India using a high resolution multi-model approach. Science of The Total Environment, doi: 10.1016/j.scitotenv.2013.01.051

21. Loaiciga H.A., Valdes J.B., Vogel R., Garvey J., Schwarz H.H. (1996). Global warming and the hydrologic cycle. Journal of Hydrology, Vol. 174 (1-2), pp. 83-128.

22. McGuffie K., Henderson-Sellers A. (1997). Climate Modelling Primer. Wiley, New York.

23. Miao et al. (2014). Assessment of CMIP5 climate models and projected temperature changes over Northern Eurasia. Environmental Research Letters, doi: 10.1088/1748-9326/9/5/055007.

24. Qu X., Huang G., Zhou W. (2014). Consistent responses of East Asian summer mean rainfall to global warming in CMIP5 simulations. Theoretical and Applied Climatology, doi: 10.1007/s00704-013-0995-9.

25. Raje D., Mujumdar P.P. (2011). A comparison of three methods for downscaling daily precipitation in the Punjab region. Hydrological Processes, Vol. 25 (23), pp. 3575-3589, doi: 10.1002/hyp.8083.

26. Ruosteenoja K., Tuomenvirta H., Jylhä K. (2007). GCM-based regional temperature and precipitation change estimates for Europe under four SRES scenarios applying a superensemble pattern-scaling method. Climatic Change, Vol. 81, pp. 193-208, doi: 10.1007/ s10584-006-9222-3. 
27. Saltzman B. (1985). Paleoclimatic Modeling. In. Hecht A.D. (Ed.), Paleoclimate Analysis and Modeling. Wiley-Interscience, New York.

28. Sarthi P.P., Dash S.K., Mamgain A. (2012). Possible changes in the characteristics of Indian Summer Monsoon under warmer climate. Global Planetary Change, Vol. 92-93, pp. 17-29, doi: 10.1016/j.gloplacha.2012.03.006.

29. Schoof J.T., Pryor S.C., Robeson S.M. (2007). Downscaling daily maximum and minimum temperatures in the midwestern USA: a hybrid empirical approach. International Journal of Climatology, Vol. 27 (4), pp. 439-454, doi: 10.1002/joc.1412.

30. Solaiman T.A. (2011). Uncertainty Estimation of Extreme Precipitations under Climatic Change: A Non-Parametric Approach. PhD Thesis, Department of Civil and Environmental Engineering, the University of Western Ontario.

31. Solman S.A. (2013). Regional Climate Modeling over South America: A Review. Advances in Meteorology. Available online at http://dx.doi.org/10.1155/2013/504357. (Accessed on 2014-08-12).

32. Urich P., Kouwenhoven P., Freas K., Van der Tak L. (2014). New IPCC climate models released: Understanding the planning implications for water resiliency. American Water Works Association, Vol. 106 (6), pp. 51-60.

33. Urrutia R., Vuille M. (2009). Climate change projections for the tropical Andes using a regional climate model: Temperature and precipitation simulations for the end of the $21 \mathrm{st}$ century. Journal of Geophysical Research, Vol. 114, pp. D02108, doi: 10.1029/2008JD011021.

34. Wei et al. (2009). Future cereal production in China: The interaction of climate change water availability and socio-economic scenarios. Global Environmental Change, Vol. 19, pp. 34-44, doi: 10.1016/j.gloenvcha.2008.10.006.

35. Wilby R.L., Dawson C.W. (2007). SDSM user manual- a decision support tool for the assessment of regional climate change impacts. Available online at https://copublic.lboro. ac.uk/cocwd/SDSM/main.html. (Accessed on the 2012-01-14).

36. Wilby R.L., Dawson C.W. (2013). The Statistical Downscaling Model: insights from one decade of application. International Journal of Climatology, Vol. 33, pp. 1707-1719, doi: 10.1002/joc.3544.

37. Wilby R.L., Dawson C.W., Barrow E.M. (2002). SDSM - a decision support tool for the assessment of regional climate change impacts. Environmental Modelling and Software, Vol. 17, pp. 147-159.

38. Wilby R.L., Charles S.P., Zorita E., Timbal B., Whetton P., Mearns L.O. (2004). Guidelines for Use of Climate Scenarios Developed from Statistical Downscaling Methods. IPCC Task Group on Data and Scenario Support for Impact and Climate Analysis (TGICA). Available online at http://ipcc-ddc.cru.uea.ac.uk/guidelines/index.html. (Accessed on the 2012-04-13).

39. Yarnal B., Comrie A.C., Frakes B., Brown D.P. (2001). Developments and Prospects in Synoptic Climatology. International Journal of Climatology, Vol. 21, pp. 1923-1950. 


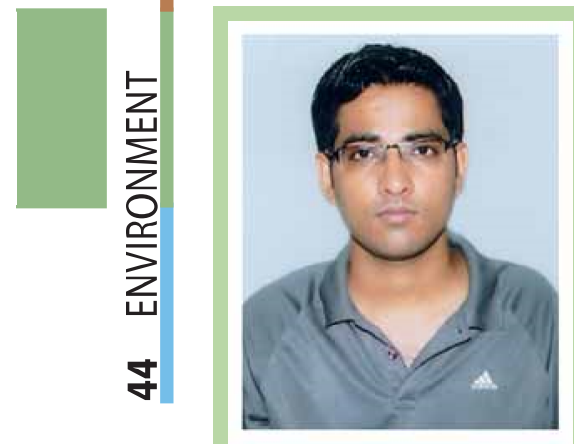

Dharmaveer Singh is currently pursuing Ph.D. in the field of Geoinformatics in the Department of GIS Cell of Motilal Nehru National Institute of Technology, Allahabad, India. He has received his B.Sc. (Hons.) degree in 2007 and M.Sc. degree in 2009 in Geography (with specialization in Remote Sensing and Cartography) from Banaras Hindu University, Varanasi, India. He has four years of experience in field of research. He has published 08 papers in refereed journals and conference proceedings. His research interest includes hydro-climatology, hydrological modelling, water resource management and application of GIS and Remote Sensing in disaster management. He is life member of Indian Association of Hydrologist (IAH). He has been awarded Junior Research Fellowship in the field of Earth Science by Council of Scientific and Industrial Research (CSIR), India.

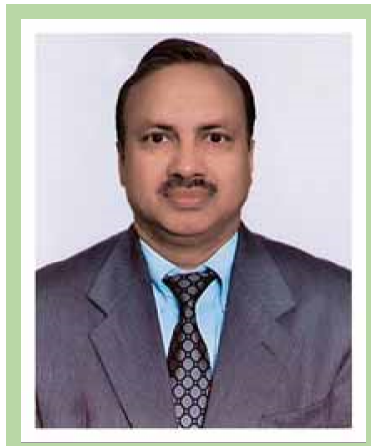

Sanjay K. Jain has received Ph.D. from Department of Earth Science, Indian Institute of Technology Roorkee, Roorkee, India in 2001 and M.S. in Hydrology from National University of Ireland, Galway, Ireland in 1997. He has more than twenty five years of experience in field of research. He is working as a scientist-F in Water Resources System division at National Institute of Hydrology, Roorkee, India and Officer-in-Charge of Indian National Committee on Climate Change (INCCC). He has 30 papers in refereed International Journals. He conducts research dealing with hydrological modeling, snow cover/ glacier mapping and snowmelt runoff modeling and impact of climate change on water resources. Dr. Jain is life member of Indian Association of Hydrologist, Indian Society of Remote Sensing, Indian Water Resources Society and International Association of Hydrological Society. He received best scientist award of National Institute of Hydrology for the year 2000.

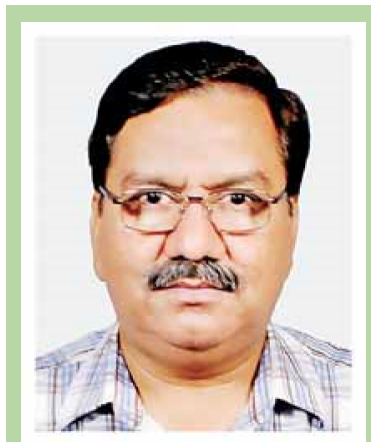

R.D. Gupta is Professor in Department of Civil Engineering, Motilal Nehru National Institute of Technology, Allahabad (India) having specialization in Geoinformatics. Prof. Gupta obtained his B.E. (Civil) in 1985, M.E. (Remote Sensing \& Photogrammetric Engineering) in 1990 and Ph.D. (Geoinformatics) in 2002, all from Indian Institute of Technology (IIT) Roorkee, India. He worked as Founding Coordinator for GIS Cell of the Institute and developed M. Tech. (GIS and Remote Sensing) course which was started under GIS Cell from the academic year 2006-07. He worked as Coordinator for signing of MoU between AIT Bangkok \& MNNIT Allahabad in November 2010 to enable better academic interaction. He worked as one of the Investigators for ISPRS and ISRO Cartosat-1 Scientific Assessment Programme (C-SAP) for the evaluation of PAN Stereo data for Test Site of Catalonia, Spain along with Dr. Manfred Lehner of DLR, Germany. He is presently working as Chief Coordinator for AICTE sponsored National Coordinated Project (NCP) on "GIS for development of Web based Public Health Information Infrastructure \& Management System". He has teaching and research experience of over 26 years. He visited several foreign countries for research paper presentation and academic interaction including Tampa (USA), Spain, Thailand, Atlanta (USA) and Suzhou (China). He has published 70 research papers in refereed journals and conference proceedings and has supervised Ph.D. and M. Tech thesis works in the field of Geoinformatics 